\title{
MINISTERIO PÚBLICO. PRINCIPIOS QUE INFORMAN EL ACCIONAR PÚBLICO
}

\author{
Roberto Saldías Pizarro
}

\section{INTRODUCCIÓN}

En noviembre de 1996, el Ejecutivo envió al Senado un proyecto de reforma constitucional con el fin de crear el Ministerio Público. ${ }^{1}$

En su mensaje, luego de expresar que junto con la Ley Orgánica Constitucional del Ministerio Público, "representa el soporte a partir del cual se estructurará un auténtico sistema acusatorio, reemplazando de esta forma el actual modelo de persecución criminal basado en una estructura eminentemente de corte inquisitorial "2, el Ejecutivo en síntesis señaló las siguientes ideas matrices en torno al referido proyecto.

a)- Separación entre las funciones de investigar y las de juzgar, entregando a órganos distintos cada una de ellas.

La reforma procesal penal "entrega la función de investigar a un órgano nuevo denominado Ministerio Público, encargado, por ende, de la persecución penal pública, que deberá a estos efectos, conducir y dirigir la investigación penal, dirigir y coordinar la labor de los organismos policiales y posteriormente formular y sustentar la acusación ante los tribunales del crimen, representando los intereses de la comunidad en la persecución de los delitos." 3

b)- Reemplazo del actual sistema inquisitivo por un sistema auténticamente adversarial y acusatorio.

En lo fundamental se intenta estructurar un proceso con igualdad de condiciones para las partes litigantes. "... enfrentando al Acusado y al cusado en un proceso genuinamente imparcial, donde la figura del juez se reserva la función de juzgar y fallar de acuerdo al mérito de las pruebas presentadas por las partes, juzgando como tercero imparcial y con arreglo a un sistema de valoración de la prueba de sana crítica" ${ }^{4}$.

De este modo, por una parte, actuará el Ministerio Público en representación de los intereses de la comunidad en la persecución del delito y que representará asimismo los derechos de las víctimas del delito; en tanto que la otra parte, estará representada por el imputado y su abogado defensor $y$, en caso que el imputado no cuente con me-

\footnotetext{
${ }^{1}$ Mensaje 98-334, de 15 de noviembre de 1996, dirigido al Presidente del Senado.

${ }^{2}$ Mensaje 98-334, de 15 de noviembre de 1996, pag. 1.

${ }^{3}$ Mensaje 98-334, de 15 de noviembre de 1996, pag. 2

${ }^{4}$ Mensaje 98-334, de 15 de noviembre de 1996, pag. 2 y 3.
} 
dios para financiar un abogado particular, será responsabilidad y obligación del Estado proporcionarle un abogado defensor en forma gratuita. ${ }^{5}$

\section{c)- Independencia respecto de otros poderes del Estado}

Después de realizar un breve análisis acerca de la ubicación Institucional del Ministerio Público, el Mensaje concluye señalando "que asimismo permite la instauración de un sistema acusatorio con una fiscalía autónoma a cargo de la instrucción, que se sujeta a un conjunto de controles y normas sobre responsabilidad, que balancean adecuadamente el grado de autonomía de que se reviste "6 7

La Ley N 19.519, publicada en el Diario Oficial del 16 de septiembre de 1997 , modificó la Constitución Política, agregando el Capítulo VI -A.

Su artículo $80^{\circ} \mathrm{A}$, inciso primero, prescribe :

"Un organismo autónomo, jerarquizado, con el nombre de Ministerio Público, dirigirá en forma exclusiva la investigación de los hechos constitutivos de delito, los que determinen la participación punible y los que acrediten la inocencia del imputado y, en su caso, ejercerá la acción penal pública en la forma prevista por la ley. De igual manera, le corresponderá la adopción de medidas para proteger a las víctimas y a los testigos. En caso alguno podrá ejercer funciones jurisdiccionales".

A su vez, el artículo $80^{\circ} \mathrm{B}$, encargó a una ley orgánica constitucional determinar la organización y atribuciones del Ministerio Público; su grado de independencia y autonomía; calidades y requisitos que deben cumplir los fiscales para su nombramiento; las causales de remoción de los fiscales adjuntos, en lo no contemplado en la constitución y, la responsabilidad que tendrán los fiscales en la dirección de la investigación y en el ejercicio de la acción penal pública, en los casos que tengan a su cargo.

Finalmente, el 15 de Octubre de 1999, se publicó en el Diario Oficial la ley $N^{\circ}$ 19.640, Orgánica Constitucional del Ministerio Público.

El artículo $1^{\circ}$ de la ley 19.640 , en la parte que aquí interesa prescribe:

"El Ministerio Público es un organismo autónomo y jerarquizado...

Ahora bien, al enviar al Parlamento el proyecto de ley que lo creaba, el Ejecutivo señaló: " ... se concibe como un órgano constitucionalmente autónomo y jerarquizado, el que se le otorga plena independencia para el cumplimiento de sus funciones "8.

\footnotetext{
${ }^{5}$ Mensaje citado, pags. 2 y 3.

${ }^{6}$ Mensaje citado, pags. 4 y 5 .

${ }^{7}$ Ver al respecto...

${ }^{8}$ Mensaje 11-337, de 23 de marzo de 1998, dirigido al Pdte. Cámara de Diputados, pp. 2.
} 
En lo que dice relación con la naturaleza de este órgano, cualquier duda que pudiera surgir a este respecto, se disipa al tener presente que después de escuchar la exposición del representante el Ministerio de Justicia, señor Mauricio Decap, quién recordó que al reformarse la Constitución de 1980, la ubicación institucional del Ministerio Público fue objeto de un profundo debate, oportunidad en la cual se optó por dejarlo como un organismo autónomo, en el mismo sentido del Tribunal Constitucional, y no de la Contraloría General de la República o del Banco Central, que sí pertenecen a la Administración del Estado; en tanto que el Tribunal Constitucional tiene la característica de ser independiente de todo otro poder del Estado, la Comisión acogió la idea de que el "Ministerio Público es un órgano que, aunque participa de la personalidad jurídica del Estado, se ubica dentro de aquellos de carácter autónomo, creados por la Constitución Política de 1980 para el cumplimiento de funciones determinadas".

En consecuencia, el Ministerio Público es independiente de los Poderes Legislativo y Judicial y no pertenece a la Administración del Estado.

\section{PRINCIPIOS QUE INFORMAN EL ACCIONAR DEL MINISTERIO PÚBLICO}

A continuación se realizará un breve análisis de los principales principios que informan el accionar del Ministerio Público.

El orden en que se abordan no dice relación con la primacía de unos sobre otros, como tampoco que un determinado principio tenga una mayor importancia que los restantes, toda vez que sólo el cumplimiento integral de todos ellos resulta acorde con la vigencia de un Estado de Derecho.

$1^{\circ}$.- Ejerce sus Funciones por medio de Organos propios y con independencia de los Poderes del Estado.

Principio consagrado en los artículos $80 \mathrm{~A} ; 80 \mathrm{~B} ; 80 \mathrm{C} ; 80 \mathrm{D}$ y $80 \mathrm{~F}$ de La Constitución Política y artículo $1^{\circ}$ de la ley $19.640 .^{9}$

Como se indicó anteriormente, el Ministerio Público es independiente de los poderes del estado y no pertenece a la Administración del Estado.

$2^{\circ}$.- Principio de Unidad de Actuación y de dependencia jerárquica

Por expresa disposición del artículo $2^{\circ}$, inciso $1^{\circ}$, de la ley 19.640 , el Ministerio Público realiza sus actuaciones procesales "a través" de cualquiera de los fiscales que intervenga en ellas ${ }^{10} \mathrm{En}$ otros términos, los fiscales no actúan en representación del

9 Ver cita $\mathrm{N}^{\circ} 8$

10 Al analizar el artículo $3^{\circ}$ del Proyecto, en la actualidad art. $2^{\circ}$, la Comisión de Constitución, Legislación. Justicia y Reglamento del Senado, sustituyó la expresión "en representación " por la utilizada finalmente, por estimar que resultaba impropia toda vez que el Ministerio Público carecia de personalidad jurídica. Boletín citado, pp. 8. 
Fiscal Nacional, sino en virtud de su nombramiento y, por ende, de la competencia que en forma expresa les otorga la ley.

La unidad de actuación se expresa, a su vez, en la facultad que posee el Fiscal Nacional para fijar, oyendo previamente al Consejo General, los criterios de actuación del Ministerio Público para el cumplimiento de los objetivos establecidos en la Constitución y las Leyes.

A este respecto, cabe tener presente que según dispone la letra a) inciso $2^{\circ}$, del artículo 17 de la ley, al Fiscal Nacional le corresponde dictar las instrucciones generales que estime conveniente para la adecuada investigación de los hechos punibles, el ejercicio de la acción penal, y la protección de las víctimas y testigos. En todo caso, dichas instrucciones necesariamente deben ser de índole general, no pudiendo referirse a casos particulares. En forma expresa se le prohibe "dar instrucciones, ordenar realizar u omitir la realización de acciones en casos particulares", con la sola salvedad de lo señalado en el artículo 18.

A su vez el artículo 21, inciso final impone al Fiscal Nacional la obligación que en la cuenta que debe rendir en el mes de abril de cada año, de a conocer "los criterios de actuación " que se aplicarán durante el período siguiente.

En consecuencia, es lícito afirmar que el principio de unidad de actuación y de dependencia jerárquica, busca que los fiscales cuando actúan en los asuntos de su competencia, prescindan de sus criterios personales y asuman aquellas posiciones que pueden definirse como "el criterio institucional del Ministerio Público"

En este sentido el profesor Juan Bustos expresa que la unidad de actuación y dependencia jerárquica dice relación con " ... todas las cuestiones técnicas y de táctica y estrategia han de surgir del cuerpo de instrucciones y del principio de obediencia jerárquica. Pero, ello, en modo alguno, puede ser obstáculo a la independencia de los fiscales en sus "decisiones jurídicas". No hay que confundir Unidad y dependencia, que dicen relación con cuestiones orgánicas institucionales y administrativas, con la función jurídica del fiscal, que para ser imparcial necesariamente ha de estar fundada en la independencia de su opinión jurídica.

No son pues conceptos contrapuestos los de imparcialidad e independencia en la función de resolución jurídica, por una parte, con los de unidad institucional y dependencia jerárquica por la otra ". ${ }^{11} /{ }^{12}$

11 BUSTOS R, Juan. "La configuración Institucional y Orgánica del Ministerio Público", pp. 215, en El Ministerio Público, CONOSUR, 1995.

12 Durante el debate de la Comisión de Constitución, Legislación, Justicia y Reglamento del senado, los representante del Ejectivo expresaron "... el Ministerio Público es un órgano jerarquizado, con unidad de actuación, y en virtud de tal jerarquía existe la facultad del Fiscal Nacional de impartir instrucciones que deben ser cumplidas por los órganos inferiores. Pero dichas instrucciones son de carácter técnico y recaen sobre aspectos de procedimiento - como la forma de recoger la prueba - que en principio se aplican de manera general. La facul- 
En todo caso, con el fin de salvaguardar la independencia de los fiscales, el Legislador estableció los siguientes mecanismos:

El artículo $2^{\circ}$, inciso $2^{\circ}$ de la ley dispone que los fiscales, en los casos que tengan a su cargo, dirigirán la investigación y ejercerán la acción penal pública con el grado de independencia, autonomía y responsabilidad que establece la ley.

Al Fiscal Nacional, como ya se expresó, se le prohibe dar instrucciones u ordenar realizar u omitir realizar actuaciones en casos particulares, con la sola salvedad de lo estipulado en el artículo $18 \mathrm{y}$, finalmente, la ley consagra el principio de obediencia reflexiva, el que por su importancia será tratado más adelante.

\section{$3^{\circ}$.- Principio de Oportunidad}

Este principio se encuentra consagrado, al menos por ahora, en el artículo 244 del Proyecto del Código Procesal Penal.

En el ejercicio de este principio, los fiscales del Ministerio Público, pueden no iniciar la persecución penal o abandonar la ya iniciada, cuando se tratare de hechos que, por su insignificancia, no comprometiere gravemente el interés público.

La ley, prohibe su ejercicio cuando la pena mínima asignada al delito excediere la de presidio o reclusión menor en su grado mínimo o se tratare de un delito cometido por un funcionario público en el ejercicio de sus funciones.

En el ejercicio de este principio los fiscales deben ajustarse "a las políticas generales del Servicio y a las normas que hubieren sido dictadas al respecto "; además, para estos efectos el fiscal debe dictar una decisión motivada y comunicarla al Juez de Control de la Instrucción, el que, a su vez, la notificará a los intervinientes si los hubiere. control.

De este modo, el ejercicio de este principio se encuentra sometido a un triple

Primero, el Fiscal que no desee iniciar la persecución penal o abandonar la ya iniciada, debe efectuarlo mediante una decisión motivada que, necesariamente, debe ajustarse a las políticas generales del Servicio y a las normas que hubieren sido dictadas conforme a ello.

Segundo, el Juez de Control de la Instrucción, dentro de los diez días siguientes, de oficio o a petición de cualquiera de los intervinientes puede dejarla sin efecto si estimare que se ha excedido de sus atribuciones 0 , cuando la víctima, dentro del mismo plazo manifestare de cualquier modo su interés en el inicio o en la continuación de la persecución penal.

tad para dictar instrucciones generales no puede ser de tal extensión que el Fiscal nacional sea quien determine el curso de una investigación en particular... "Boletín citado, pag. 24. 
Tercero, una vez vencido el plazo de diez días o una vez rechazada por el juez la reclamación respectiva, los intervinientes cuentan con un nuevo plazo de diez días para impugnar la decisión del fiscal ante las autoridades del Ministerio Público.

La ley Orgánica Constitucional del Ministerio Público, en sus artículos 32, letra b) y 33 , tratan esta materia. En síntesis disponen que la reclamación que acorde a la ley procesal penal puede deducir cualquier interviniente en contra de un Fiscal Adjunto debe efectuarse por escrito ante el Fiscal Regional quién debe resolverla también por escrito dentro del plazo de cinco días hábiles.

Si bien la ley no contempla un recurso en contra de la resolución que pudiere dictar un Fiscal Regional, es indudable, que quién se sienta afectado por dicha resolución, podrá recurrir ante el Fiscal Nacional solicitando la reconsideración de la misma.

\section{$4^{\circ}$ - Imparcialidad y Objetividad}

El principio de imparcialidad y objetividad se encuentra consagrado en diferentes normas de la ley. En efecto, el artículo $1^{\circ}$ luego de señalar que le corresponde al Ministerio Público la función de dirigir en forma exclusiva la investigación de los hechos que revisten las características de delito, los que determinen la participación punible, añade que también le corresponde investigar "los que acrediten la inocencia del imputado".

El artículo $2^{\circ}$, inciso $2^{\circ}$, en forma explícita dispone que los fiscales en los casos que tengan a su cargo, dirigirán la investigación y ejercerán la acción penal pública con el grado de independencia, autonomía y responsabilidad que les otorga la ley.

Finalmente, el artículo $3^{\circ}$ dispone que los fiscales adecuarán sus actos a un criterio objetivo, velando únicamente por la correcta aplicación de la ley y, acorde con dicho criterio, se encuentran obligados a investigar con igual celo no sólo los hechos y circunstancias que funden o agraven la responsabilidad del imputado, sino también los que la eximan, la extingan o la atenúen.

Por su parte, el Proyecto del Código Procesal Penal, en su artículo 94 repite la norma precitada.

Sin perjuicio de lo anterior, con el objeto de asegurar la imparcialidad y objetividad de los fiscales, la ley en su artículo 55 contempla las causales de inhabilitación para dichos funcionarios y, en sus artículos siguientes, detalla el procedimiento al que deben ceñirse los fiscales en esta materia.

Por último, entre las prohibiciones a que están afectos estos personales, el artículo 63, letra d), prohibe expresamente "Efectuar actuaciones que priven al imputado o a terceros del ejercicio de los derechos que la Constitución asegura, o lo restrinjan o perturben sin autorización judicial previa...". 


\section{$5^{\circ}$ Responsabilidad y Obediencia Reflexiva}

En estrecha relación con los principios de unidad de actuación, dependencia jerárquica e imparcialidad y objetividad, los fiscales del Ministerio Público poseen responsabilidad civil, disciplinaria y penal por los actos realizados en el ejercicio de sus funciones.

En lo que respecta a la responsabilidad civil, sin perjuicio de volver a ella al momento de analizar las implicancias que tiene la declaración consignada en el artículo 90 de la ley, por ahora es menester recordar que la Constitución Política en su artículo 38 inciso $2^{\circ}$, prescribe "Cualquier persona que sea lesionada en sus derechos por la Administración del Estado, de sus organismos o de las municipalidades, podrá reclamar ante los tribunales que determine la ley, sin perjuicio de la responsabilidad que pudiere afectar al funcionario que hubiere causado el daño".

No obstante que la norma se refiere a la Administración del Estado o de sus organismos, a juicio del suscrito, la responsabilidad extracontractual del Estado que consagra la Carta Fundamental resulta aplicable en la especie, toda vez que resulta atentatorio al principio de igualdad ante la ley, que la responsabilidad extracontractual del Estado por el daño que pudiere ocasionar un agente público quedara circunscrito a que éste perteneciere a la Administración del Estado y no resultara aplicable a los órganos autónomos creados por la Constitución.

Sin perjuicio de lo anterior, el artículo $5^{\circ}$, inciso $1^{\circ}$, de la Ley dispone que el Estado será responsable por las conductas injustificadamente erróneas o arbitrarias del Ministerio Público, añadiendo que la acción para perseguir el daño prescribirá en cuatro años, contados desde la fecha de la actuación dañina ${ }^{13}$.

En lo que dice relación con la responsabilidad disciplinaria de los fiscales, cabe recordar que ésta tiene su origen en una falta cometida por un agente público en el ejercicio de sus funciones $y$, que por lo mismo, es susceptible de una sanción disciplinaria.

Con este objeto, la ley ha estipulado por una parte, un conjunto de obligaciones y prohibiciones aplicables a los fiscales y, por otra parte, ha establecido las sanciones a aplicar y el procedimiento que debe seguirse para estos efectos.

En términos generales puede señalarse que la responsabilidad disciplinaria de los fiscales por actos realizados en el ejercicio de sus funciones corresponde hacerla efectiva a la autoridad superior respectiva.

Con este objeto, la ley en su artículo 51 detalla el procedimiento a seguir. En síntesis, éste es del todo semejante a la denominada "Investigación Sumaria" estable-

13 La Comisión de Constitución, Legislación, Justicia y Reglamento del Senado optó por hacer referencia a " conductas "en el entendido de que, en esa forma, se comprende tanto las acciones como las omisiones de este organismo. Boletín citado pag. 5. 
cida en los Estatutos Administrativos aplicables a los empleados públicos y empleados municipales. ${ }^{14}$ Se caracteriza por ser un procedimiento breve y fundamentalmente oral, sin más formalidad que levantar un acta de lo actuado que firman quienes hayan declarado y sin perjuicio de agregar los documentos probatorios que correspondan. La etapa de investigación propiamente tal no puede exceder de cinco días hábiles, al término de los cuales el Investigador debe formular el o los cargos que procedan, notificándolos al afectado, quién debe responderlos dentro de dos días hábiles contados de su notificación. Si el inculpado ofreciere rendir prueba, el investigador debe abrir un término probatorio el que no puede exceder de tres días hábiles.

Vencido el plazo para los descargos o, en su caso, el término probatorio, el investigador procederá, dentro de los dos días siguientes, a emitir un informe que contendrá la relación de los hechos, los fundamentos y conclusiones a que hubiere llegado y formulará a la autoridad respectiva (Fiscal Regional si se tratare de un Fiscal Adjunto o Fiscal Nacional si el inculpado fuere un Fiscal Regional) la proposición que estimare procedente. Conocido el informe y dentro de los dos días hábiles siguientes, la Autoridad dictará la resolución que correspondiere, la que será notificada al afectado. De ésta se puede apelar ante el Fiscal Nacional o, solicitarse la reconsideración si el afectado fuere un Fiscal Regional.

Si bien la ley no contiene normas acerca de los requisitos que deben cumplir los cargos que se formulen, como tampoco, la forma en que debe efectuarse las notificaciones y la posibilidad de recusar al investigador, se estima que a fin de salvaguardar el derecho a defensa de que goza el inculpado, el Fiscal Nacional en los reglamentos que dicte en el ejercicio de la superintendencia directiva, correccional y económica de que está investido, debe precisar estos aspectos.

En lo que dice relación con el o los cargos que se formulen, no cabe duda que éstos deben ser precisos, detallando en forma concreta la o las infracciones que se imputan como única forma de que el inculpado pueda ejercer real y efectivamente su derecho a defensa, pues en el caso de que éstos sean genéricos el derecho a defensa resulta ilusorio.

En cuanto a la forma de practicar las notificaciones, se estima que, al menos, la primera de ella debe efectuarse en forma personal dando copia íntegra de la resolución respectiva. Sólo en el evento de no ser habido en su domicilio o en su lugar de trabajo y. previa búsqueda, procedería notificarlo por carta certificada dirigida al último domicilio registrado en la Institución.

Finalmente, procedería reconocer como causales de implicancia o recusación el tener interés directo o indirecto en los hechos que se investigan: amistad o enemistad manifiesta con el inculpado o estar ligado a él por un vínculo de parentezco cercano. (padre, hijo, adoptado, cónyuge, etc.).

${ }^{14}$ Ley 18.834 y 18.883 , respectivamente 
En cuanto a las medidas disciplinarias a aplicar, el artículo 49 contempla las siguientes: Amonestación; Censura por escrito; Multa equivalente hasta media remuneración mensual, por el lapso de un mes; suspensión de funciones hasta por dos meses, con goce de media remuneración y la Remoción.

Según lo dispone el artículo 50, las medidas disciplinarias antes indicadas se aplicarán tomando en cuenta la gravedad de la falta cometida, la eventual reiteración de la conducta y las circunstancias atenuantes y agravantes que arroje el mérito de los antecedentes.

La remoción de un Fiscal Adjunto procede cuando incurre en alguna de las siguientes causales: 1).- Incapacidad, mal comportamiento o negligencia manifiesta en el ejercicio de sus funciones; 2).- Falta de probidad, vías de hecho, injurias o conducta inmoral grave, debidamente comprobada; 3 ).- Ausencia injustificada a sus labores, o sin aviso previo, si ello significare un retardo o perjuicio grave para las tareas encomendadas y 4).- Incumplimiento grave de sus obligaciones, deberes o prohibiciones.

No obstante lo anterior, el Fiscal Nacional y los Fiscales Regionales, por expresa disposición del artículo 53, sólo pueden ser removidos por la Corte Suprema a requerimiento del Presidente de la República; de la Cámara de Diputados o de diez de sus miembros por incapacidad, mal comportamiento o negligencia manifiesta en el ejercicio de sus funciones. Además, tratándose de los Fiscales Regionales, la remoción puede solicitarla el Fiscal Nacional.

En lo atingente a la responsabilidad penal de los fiscales, el artículo 46 de la ley regula esta materia indicando: "Presentada una denuncia en contra de un fiscal del Ministerio Público por su presunta responsabilidad en un hecho punible, o tan pronto aparezcan antecedentes que lo señalen como partícipe en un delito, corresponderá dirigir las actuaciones del procedimiento destinado a perseguir la responsabilidad penal:

a) Sesión del Consejo General, la que será especialmente convocada y presidida por el Del Fiscal Nacional, al Fiscal Regional que se designe mediante sorteo, en Fiscal Regional más antiguo.

b) De un Fiscal Regional, al Fiscal Regional que designe el Fiscal Nacional, oyendo previamente al Consejo General, y

c) De un Fiscal Adjunto, al Fiscal Regional que designe el Fiscal Nacional.

Tratándose de delitos cometidos por un fiscal en el ejercicio de sus funciones, el fiscal a cargo de la investigación deducirá, si procediere, la respectiva querella de capítulos, conforme a las disposiciones de la ley procesal penal".

En lo que dice relación con el principio de obediencia reflexiva, cabe consignar que tanto el Estatuto Administrativo para los Funcionarios Públicos (ley 18.834) como el Estatuto Administrativo de los Empleados Municipales (ley 18.883) lo contemplan como una circunstancia eximente de responsabilidad administrativa. 
En dichos cuerpos normativos se faculta al empleado para representar por escrito al superior jerárquico las órdenes ilegales que éste hubiere impartido.

Como se verá a continuación, la ley 19.640 da un tratamiento más amplio a este principio, toda vez que no lo limita exclusivamente a las ordenes ilegales, sino que la representación procede por estimarla improcedente o, por ser contrarias a la ética profesional.

El artículo 35 regula la obediencia reflexiva respecto de los Fiscales Regionales, señalando como regla general que éstos deben dar cumplimiento a las instrucciones generales impartidas por el Fiscal Nacional.

No obstante, si las instrucciones incidieren en el ejercicio de las facultades de dirigir la investigación o en el ejercicio de la acción penal pública, los Fiscales Regionales pueden objetarlas por razones fundadas.

Como queda de manifiesto no se trata de objetar la orden impartida por el superior por estimarla ilegal, sino por considerar que interfiere en su facultad de dirigir la investigación o en el ejercicio de la acción penal pública. Vale decir, las razones que fundamentan la representación pueden incidir, incluso, en aspectos de mérito u oportunidad.

Con todo, añade la ley, si la instrucción objetada incide en actuaciones procesales que no pudieren dilatarse, el Fiscal Regional se encuentra en el imperativo de realizarlas en tanto la objeción no sea resuelta.

En los casos en que el Fiscal Nacional acogiere la objeción, se encuentra obligado a modificar la instrucción con efectos generales para todo el Ministerio Público. Si la rechazare, asume la plena responsabilidad debiendo el Fiscal Regional dar cumplimiento a lo resuelto sin más trámite.

Respecto de lo Fiscales Adjuntos, el artículo 44 de la ley luego de disponer que se encuentran obligados a acatar las normas legales y las instrucciones generales que, dentro del ámbito de su competencia, imparta el Fiscal Nacional o Regional, en su inciso $2^{\circ}$ añade que estarán igualmente obligados a obedecer las instrucciones particulares que el Fiscal Regional les dirija con respecto a un caso que les hubiere sido asignado. En esta última situación se encuentran facultados para representar la orden fundados en alguna de las siguientes circunstancias: a) que se tratare de una orden ilegal, b) por estimarla manifiestamente arbitraria y c) por considerarla contraria a la ética profesional.

En todos estos casos la representación debe efectuarse por escrito y dentro de las 24 horas siguientes a la recepción de la orden y el Fiscal Regional debe resolver por escrito la objeción.

Si la acoge, el Fiscal Adjunto continuará desempeñando sus funciones acorde las instrucciones generales. En caso contrario, deberá cumplir la instrucción asumiendo la plena responsabilidad el Fiscal Regional. 
Al igual que en el caso de los Fiscales Regionales, si se tratare de actuaciones procesales impostergables, el Fiscal Adjunto deberá darles cumplimiento sin perjuicio de la objeción que pudiere formular.

\section{6.- Probidad, Transparencia y Publicidad}

La probidad en términos generales es la rectitud y moralidad a que tiene que ajustarse la conducta humana. En el ámbito de lo público viene a ser la conducta que debe observarse en el cumplimiento de las funciones públicas.

Según el Diccionario de la Lengua Española, tiene su origen en la palabra "probitas "que significa bondad, rectitud de ánimo, hombría de bien, integridad y honradez en el obrar. Es sinónimo de honorabilidad.

En una conceptualización restringida, la probidad quedaría circunscrita sólo a la conducta moral del sujeto como sinónimo de honradez; sin embargo, en el campo del derecho público la probidad sería un concepto de mayor riqueza, por cuanto supone, además, de la rectitud un cumplimiento cabal del comportamiento debido y justo ${ }^{15}$.

Por otra parte, y en estrecha relación con este principio, es del caso recordar que la Comisión Nacional de Ética Pública ${ }^{16}$ en su Informe páginas 6 y 7 dice que la probidad pública "se refiere a la integridad en el cumplimiento de las obligaciones y deberes propios y anexos a los cargos y funciones públicas "

Añade el informe que se extiende "a la responsabilidad pública, en su acepción de obligación del agente público de responder por el desempeño de sus funciones ante la sociedad civil". "La responsabilidad pública, en consecuencia, es la cualidad de aquel que da cuenta ante quien corresponde, sobre el ejercicio de la función que le ha sido atribuida", "de este modo, la responsabilidad es parte de la probidad, con relación a quién, en última instancia, está encargada de evaluar y juzgarla: la ciudadanía".

Finalmente, el Informe concluye señalando que las conductas y acciones de los agentes públicos deben estar "expuestas a la vista y conocimiento de la sociedad civil ", de lo que nace el carácter de "transparencia " que a su vez complementa el principio de probidad.

Ahora bien, el artículo $8^{\circ}$, inciso $1^{\circ}$ de la ley, sin dar una definición o concepto se limita a prescribir: "Los fiscales y funcionarios del Ministerio Público deberán observar el principio de probidad administrativa",

Ante la ausencia de dicho concepto y, sin perjuicio de lo señalado con anterioridad, es del caso recordar que dicho principio se encuentra consagrado en el artículo $7^{\circ}$

15 En este sentido el Profesor de Derecho Administrativo, don Jorge Reyes Riveros se pronuncia, citando para estos efectos el trabajo inédito del señor Contralor general de la República, don Arturo Aylwin Azócar "Algunas ideas sobre Probidad en la Función Pública"

Creada por Decreto $N^{\circ} 423$, de 18 de abril de 1994 , del Ministerio del Interior. 
de la ley 18.575 Orgánica Constitucional de Bases Administrativas Generales de la Administración del Estado y es entendido como "una conducta moralmente intachable y una entrega honesta y leal al desempeño del cargo, con preeminencia del interés público sobre el privado".

Se relacionan preferentemente con este principio las siguientes prohibiciones:

Ejercer la profesión de abogado, salvo las excepciones contempladas en el artículo 63, letra a).

Intervenir, en razón de sus funciones, en asuntos en que tengan interés personal o en que lo tengan el cónyuge, hijos, adoptados o parientes en el grado en que se indica en la letra b) del mismo artículo. Norma que en todo caso debe relacionarse con el artículo 240 del Código Penal que tipifica el delito de negociación incompatible.

Solicitar, hacerse prometer, aceptar o recibir cualquier tipo de pago, prestación, regalía, beneficio, donativo, ventaja o privilegio, de cualquier naturaleza, para sí o para terceros, de parte de cualquier persona, natural o jurídica, con la cual deban relacionarse de cualquier modo, en razón del desempeño de sus funciones.

Incurrir, a sabiendas, en alguna causal de inhabilitación, o permitir que incurran en ella su cónyuge o alguno de los parientes que pueden generarla.

En relación con esta última prohibición, se estima poco adecuado el que pueda llegar a sancionarse "el permitir" que incurran en alguna causal de inhabilitación el cónyuge y los parientes que pueden generarla, toda vez que resulta probable que en más de una oportunidad el fiscal no podrá impedir que alguno de sus parientes incurra en alguna causal de inhabilitación y, por ende, no correspondería formular un juicio de reproche por tal concepto.

Las restantes prohibiciones contempladas en el artículo 63, pueden llegar a constituir una falta de probidad según sean las circunstancias que concurran en cada caso particular.

En lo que respecta a la Transparencia, previo a analizar las normas que la consagran, cabe recordar que para la Comisión Nacional de Etica Pública este concepto forma parte integrante de la probidad.

Se encuentra consagrada en el artículo $8^{\circ}$, incisos $2^{\circ}$ y $3^{\circ}$, en virtud de los cuales las funciones que la ley encomienda al Ministerio Público deben ejercerse con transparencia, de manera que permita y promueva el conocimiento de los procedimientos, contenidos y fundamentos de las decisiones que se adopten en el ejercicio de ellas. Para lo anterior, la ley dispone que el Ministerio Público adoptará las medidas tendientes a asegurar el adecuado acceso a los fiscales por parte de cualquier interesado, con pleno respeto a sus derechos y dignidad personal 
Con el fin de asegurar la transparencia, los artículos 21 y 36 imponen al Fiscal Nacional y Fiscales Regionales la obligación de rendir cuenta pública en los meses de abril y enero, respectivamente.

Especial importancia reviste la cuenta pública que debe rendir el Fiscal Nacional, ya que al margen de dar a conocer los resultados obtenidos en las actividades realizadas, el uso de los recursos, las dificultades que se hubieren presentado, en dicha oportunidad debe "dar a conocer los criterios de actuación del Ministerio Público que se aplicarán durante el período siguiente".

Igualmente, se relaciona con la transparencia la declaración jurada de intereses a que se refiere el artículo $9^{\circ}$ y, en cuya virtud, el Fiscal Nacional y los Fiscales Regionales y Adjuntos deberán, dentro del plazo de treinta días contado desde que hubieren asumido el cargo, efectuar una declaración jurada de intereses ante un notario de la ciudad donde ejerzan sus funciones, o ante el Oficial del Registro Civil en aquellas comunas en que no hubiere notario. Declaración que debe en todo caso actualizarse cada cuatro años si con antelación no se le hubiera nombrado en un nuevo cargo.

Al margen de lo señalado, la declaración debe protocolizarse en la misma notaría en que fue prestada o en una notaría con jurisdicción en el territorio de la fiscalía a que perteneciere el declarante. Una copia de la declaración protocolizada debe remitirse a la Fiscalía Nacional y otra a la respectiva Fiscalía Regional, donde se mantendrá para su consulta pública.

Por otra parte, el artículo 47 sanciona a los Fiscales Regionales y Adjuntos por la no presentación oportuna de la declaración de intereses, sanción que puede llegar inclusive a la remoción de un Fiscal Adjunto cuando éste fuere contumaz en la omisión o por "la inclusión de datos relevantes inexactos y la omisión inexcusable de la información relevante requerida por la ley".

Finalmente, la publicidad se encuentra consagrada en el artículo $8^{\circ}$, incisos $3^{\circ} \mathrm{y}$ $4^{\circ}$.

La regla general en esta materia es que son públicos los actos administrativos y los documentos que le sirven de sustento o complemento directo y esencial.

No obstante lo anterior, le ley dispone que puede denegarse la entrega de documentos o antecedentes en virtud de las siguientes causales: la reserva o secreto establecidos en disposiciones legales o reglamentarias; cuando la publicidad impida o entorpezca el debido cumplimiento de las funciones del organismo; la oposición deducida por terceros a quienes se refiera o afecte la información contendida en los documentos requeridos; que la divulgación o entrega de documentos o antecedentes afecte sensiblemente los derechos o intereses de terceras personas, según calificación fundada de la autoridad respectiva (Fiscal Nacional o Regional, según corresponda) y, por último, que la publicidad afecte la seguridad nacional o el interés nacional. 
En lo referente a la publicidad, divulgación e información de los actos relativos o relacionados con la investigación, el ejercicio de la acción penal pública y la protección de las víctimas y testigos se rige por la ley procesal penal.

Sólo a vía de ejemplo, pues un análisis exhaustivo escapa al objeto del presente trabajo, puede señalarse que el Proyecto del Código Procesal Penal en su artículo 95. letra a) impone a los fiscales la obligación de entregarle a la víctima "información acerca del curso y resultado del procedimiento, de sus derechos y de las actividades que deba realizar para ejercerlos". Respecto del imputado, en el artículo 107, letras a); y e) se le otorga el derecho de que se le informe de manera específica y clara acerca de los hechos que se le imputan y solicitar no sólo que se active la investigación, sino que, además, se le de a conocer su contenido. Si el imputado fuere sometido a prisión preventiva, el artículo 108, en sus letras a) y b) le otorga los siguientes derechos: que se le exprese específica y claramente el motivo de su privación de libertad y que se le exhiba la orden que la fundamenta, en su caso, e informar por sí mismo o que se le informe inmediatamente a su familia, a su defensor o a la persona a quien indique, por los medios más expeditos, el hecho de su detención o prisión.

A su vez, el artículo 109, dispone que los jueces, fiscales del ministerio público y los funcionarios policiales estarán obligados a dar estricto cumplimiento a lo preceptuado en los dos artículos anteriores.

Para finalizar con estos breves ejemplos, el artículo 137, entre los derechos que otorga a las víctimas en su letra b) contempla el derecho a ser informado de los resultados del procedimiento, aún cuando no hubiere intervenido en él.

\section{7.- Control}

La señora Ministro de Justicia al concurrir a la Comisión de Constitución Legislación, Justicia y Reglamento del Senado durante el segundo trámite Constitucional ${ }^{17}$, en lo que aquí interesa expresó: "... el proyecto de ley contempla un conjunto de controles, que comienzan con la remoción de los fiscales y que se complementan con otros más, considerados en el proyecto de ley sobre nuevo Código Procesal Penal"; "se han contemplado tres instancias de control del trabajo que van a llevar a cabo los fiscales. La primera es el reclamo ante la autoridad respectiva del propio Ministerio Público que puede conducir a la aplicación de sanciones disciplinarias; la segunda, se refiere al reclamo ante el juez de garantía, y por último está la posibilidad de remoción, contemplada en las disposiciones constitucionales".

Al evacuar un segundo Informe la Comisión de Constitución, Legislación, Justicia y reglamento del senado concluyó:

${ }^{17}$ Primer Informe de la Comisión antes citada, Boletín N²152-07, pags. 10 y 11. 


\section{"c) Control}

Un elemento indispensable de una buena gestión lo constituye el control, que la Comisión estableció señalando que las autoridades y jefaturas, dentro del ámbito de su competencia y en los niveles que corresponda, ejercerán un control jerárquico permanente del funcionamiento de las unidades y de la actuación de los funcionarios de su dependencia.

Añadió que este control se extenderá tanto a la eficiencia y eficacia en el cumplimiento de los fines y objetivos establecidos como a la legalidad y oportunidad de las actuaciones" $" 18$

Del estudio de la ley es dable clasificar el control de la siguiente forma:

\section{Control Interno o Jerárquico}

Según lo ordena el artículo $7^{\circ}$, las autoridades y jefaturas, dentro del ámbito de su competencia administrativa y en los niveles que corresponda, ejercerán un control jerárquico permanente del funcionamiento de las unidades y de la actuación de los funcionarios de su dependencia.

Por mandato legal este control debe extenderse a la eficiencia, eficacia, legalidad y oportunidad de las actuaciones. (artículo $7^{\circ}$, inciso final)

La eficiencia, al decir del Profesor de Derecho Administrativo don Jorge Reyes Riveros ${ }^{19}$ mira no sólo al manejo de los recursos y que deriva del deber de los agentes del Estado de velar por el mejor aprovechamiento de los recursos disponibles y que puede ser denominada como "eficiencia operativa", sino también corresponde vincularla con aquella que se orienta al funcionamiento debido, ágil, expedito y oportuno de los Servicios e Instituciones Públicas y que puede denominarse "eficiencia funcional".

La eficiencia operativa al decir del autor, supone la "eficacia"; esto es, el cumplimiento de las metas previstas en el plazo determinado; la economicidad, vale decir, la obtención de los recursos necesarios para la realización de las metas, en los mejores términos de oportunidad, y la eficiencia propiamente tal, que implica el empleo óptimo de los recursos disponibles para alcanzar las metas propuestas sobre la base de la ecuación costo - resultado.

Por su parte, la eficiencia funcional arranca o tiene su origen en el artículo $1^{\circ}$. inciso $4^{\circ}$, de la Constitución Política, toda vez que el estado está al servicio de la persona humana y su finalidad es promover el bien común, para lo cual debe contribuir a crear las condiciones sociales que permitan a todos y a cada uno de los integrantes de la comunidad nacional su mayor realización espiritual y material posible.

\footnotetext{
${ }^{18}$ Segundo Informe de la Comisión antes citada, Boletín N²152-07, pags. 5 y 6.

19 Trabajo inédito del profesor Reyes, denominado "El principio de Juricidad y la Modernidad ", pags. 35 a 38.
} 
Si bien formalmente no resulta aplicable al Ministerio Público la ley 18.575 , Orgánica Constitucional de Bases Administrativas Generales del Estado, su artículo $3^{\circ}$ al disponer que la Administración del Estado estará al servicio de la comunidad, atendiendo las necesidades públicas en forma continua y permanente; necesariamente constituye el paradigma que debe tenerse presente al reflexionar acerca de la eficiencia funcional.

Es en virtud de la eficiencia funcional que los procedimientos deben ser ágiles y expeditos, sin más formalidades que las que establezcan las leyes y procurarán la simplificación y rapidez de sus actuaciones. (artículo $6^{\circ}$, inciso final). Por idéntica razón debe existir coordinación y propender a la unidad de acción, evitando la duplicación o interferencia de sus funciones (artículo $6^{\circ}$, inciso $2^{\circ}$ ) y, finalmente, la eficiencia funcional supone un control jerárquico permanente de la eficacia y eficiencia en el cumplimiento de las metas y objetivos propuestos.

\section{Legalidad}

Como se expresó anteriormente, por mandato legal, el control jerárquico también abarca la "legalidad "y "oportunidad de las actuaciones".

En relación con este control, es del caso señalar que, en la actualidad, la doctrina prefiere el término "juricidad", entendiendo por tal "la sujección integral a Derecho de los órganos del Estado tanto en su ser como en su obrar "20.

En virtud del principio de supremacía constitucional, la actuación de los órganos del Estado deben sujetarse preferentemente a la Constitución Política, tanto a las normas que ella contiene, de aplicación directa, como a los principios que de ella emanan.

La infracción a este principio tiene como sanción la nulidad del acto, encontrándose el órgano emisor en el deber de invalidar su propio acto, mediante la dictación de otro acto que lo deje sin efecto.

No obstante, el ejercicio de esta potestad invalidatoria se encuentra restringida cuando atenta contra los principios de seguridad jurídica o de certeza que de ella deriva y de la buena fe de los terceros involucrados; esto es, cuando los terceros han actuado en la creencia de encontrarse frente a una situación regular y legítima.

\section{9.- Control Financiero}

El artículo 90, inciso $1^{\circ}$, de la Ley Orgánica Constitucional del Ministerio Público, dispone que dicho organismo "se sujetará a las normas de la Ley de Administración Financiera del Estado "; esto es, el Decreto Ley 1.263, de 1975.

20 SOTO KLOSS, Eduardo, "Derecho Administrativo, Bases Fundamentales"; Tomo II, pp. 24, Editorial Jurídica de Chile, 1996 
De conformidad con lo dispuesto en el artículo $1^{\circ}$, del DL 1.263 , de 1975 , el sistema de Administración Financiera del Estado comprende el conjunto de procesos administrativos que permiten la obtención de recursos y de su aplicación a la concreción de los logros de los objetivos del Estado. La administración financiera incluye, fundamentalmente, los procesos presupuestarios, de contabilidad y de administración de fondos.

Su título V. Se refiere al "Sistema de Control Financiero", entendiendo por éste todas las acciones orientadas a cautelar y fiscalizar la correcta administración de los recursos del Estado; verificar el cumplimiento de los fines, el acatamiento de las disposiciones legales y reglamentarias y la obtención de las metas programadas por los servicios que integran el sector público (DL 1263/75, artículo 51).

Respecto al control financiero, el artículo 52 inciso $1^{\circ}$, dispone que le corresponderá a la Contraloría General de la República “... fiscalizar el cumplimiento de las disposiciones legales y reglamentarias que dicen relación con la administración de los recursos del estado y efectuar auditorías para verificar la recaudación, percepción e inversión de sus ingresos y de las entradas propias de los servicios públicos".

Ahora bien, antes de proceder al estudio de las obligaciones que impone el citado decreto ley y las atribuciones que en esta materia posee la Contraloría General de la República, resulta necesario dilucidar cuál es la real competencia que la ley 19.640 otorga al Organo Contralor, ya que si bien su artículo 90 al señalar que el Ministerio Público se sujetará a las normas de dicha ley, hace aplicable el Título V. "DEL SISTEMA DE CONTROL FINANCIERO “y, por ende, le otorga competencia a la Contraloría General, su artículo 71 prescribe:

"No se aplicarán al Ministerio Público las disposiciones legales que rigen la acción de la Contraloría General de la República, salvo en aquellas materias en que la presente ley requiere expresamente de la intervención del órgano contralor.

El nombramiento del Fiscal Nacional y de los Fiscales Regionales estará sujeto a los trámites de toma de razón y registro por la Contraloría General de la República. Lo mismo se aplicará a los demás decretos o resoluciones que los afecten, salvo que el Contralor General los eximiere de la toma de razón.

El nombramiento de los fiscales adjuntos y la contratación de los funcionarios, así como las demás resoluciones que los afecten, se enviarán a la Contraloría General de la República para su registro".

Si bien de una primera lectura del artículo transcrito, es dable concluir que la competencia de la Contraloría General se encuentra supeditada a que la ley 19.640 requiera en forma expresa su intervención, hecho que no acontece en materia de índole financiera, una segunda lectura permite arribar a una conclusión diferente.

En efecto, el artículo 71, se encuentra inserto en el Título VI. "Normas de Personal", Párrafo $1^{\circ}$, "Relaciones estatutarias". Vale decir, el contenido y alcance de la norma se encuentra circunscrito a las materias propias de personal; en tanto que el 
artículo 90 pertenece a un título diferente, como es el Título VIII. "Presupuesto" y, por tanto, la limitación que consagra el artículo 71 no comprende las normas relativas a la administración financiera y manejo de los recursos públicos que la de presupuestos debe asignar anualmente al Ministerio Público para su funcionamiento.

Corrobora la conclusión antes dicha, el tener presente que el Ejecutivo al enviar el proyecto de ley que reformó la Constitución Política, creando el Ministerio Público. propuso el siguiente texto: "Existirá un organismo autónomo, con patrimonio propio, denominado Ministerio Público...".

Pues bien, durante su tramitación en el Senado se suprimió la mención al "patrimonio propio", según se dijo "en atención a que este atributo pertenece a las personas jurídicas de derecho público que cuentan con un capital como el Banco Central, o con ingresos propios, como los Gobiernos Regionales y las Municipalidades; en tanto que el Ministerio Público no tiene personalidad jurídica diferente de la del Fisco y será la ley anual de presupuestos la que determine el tipo y volumen de los recursos que le asignará para el cumplimiento de sus funciones, para lo cual habrá de crearse una partida específica. Además, el organismo quedará afecto al control que en estos aspectos ejerce la Contraloría General de la República".

Por otra parte, conviene recordar que la responsabilidad civil de un agente público emana, por regla general, de algunas de las siguientes circunstancias:

De un perjuicio patrimonial que el agente infiere al Estado como consecuencia de una acción u omisión culpable o dolosa.

Cuando la Institución representada por la actuación del agente causa daño a un particular, y cuando el agente público percibe un beneficio pecuniario en forma indebida.

En estrecha relación con lo señalado, cabe tener presente que la Ley $N^{\circ} 10.336$ Orgánica Constitucional de la Contraloría General de la República, contiene cuatro principios rectores en materia de responsabilidad civil.

$1^{\circ}$.- Todos los funcionarios cuyas atribuciones le permitan o exijan la tenencia, custodia o administración de fondos o bienes del Estado es responsable de éstos. (Artículo 60)

$2^{\circ}$ - Todo funcionario que tenga, custodie o administre fondos o bienes del Estado es responsable de su uso, abuso o empleo ilegal y de toda pérdida o deterioro de los mismos que se produzca y que sea imputable a su negligencia (Artículo 61).

$3^{\circ}$.- Ningún funcionario queda libre de responsabilidad derivada de la pérdida, merma, hurto o deterioro de los bienes que administre o custodie mientras el Contralor General no lo haya exonerado expresamente de dicha responsabilidad, al término del sumario respectivo (Artículo 62). 
$4^{\circ}$ - Ningún funcionario será relevado de su responsabilidad por haber procedido en virtud de orden de un funcionario superior, al pago, uso o disposición de fondos o bienes de que sea responsable, salvo que compruebe haber representado por escrito la ilegalidad de la orden recibida. (Artículo 64).

Volviendo al tema central, conviene recordar que en virtud de lo dispuesto en la ley de Administración Financiera del Estado, con miras a un adecuado control, las Instituciones regidas por dicho texto se encuentran sujetas a las siguientes obligaciones:

a).- Los recursos financieros deben manejarse en una cuenta corriente en el Banco del Estado de Chile - Cuenta Unica Fiscal Subsidiaria (artículo 6º ).

b).- El ejercicio presupuestario coincide con el año calendario y las cuentas del ejercicio presupuestario deben cerrarse al 31 de diciembre de cada año. A partir del $1^{\circ}$ de enero de cada año no puede efectuarse pago alguno sino con cargo al presupuesto vigente. En consecuencia, los compromisos pendientes al 31 de diciembre de cada año procede sean cancelados con cargo al nuevo presupuesto, en las condiciones que anualmente se fijan por decreto supremo.

El saldo final de caja al cierre del ejercicio y los ingresos que se perciban con posterioridad se incorporan al presupuesto siguiente. (artículos 12 y 24 ).

c).- Tanto los ingresos como los gastos, deben contar con el respaldo documental original que los acredita y justifique el cumplimiento de las obligaciones tributarias, de ejecución presupuestaria y de cualquier otro requisito que exijan los reglamentos o leyes especiales sobre la materia (artículo 55).

d).- Los cargos cuya función consiste en la administración y/o custodia de bienes o dineros, deberán estar debidamente identificados en la organización del Servicio y los funcionarios que los ejerzan estarán obligados a rendir caución individual o colectiva, en la forma y condiciones que determine la Contraloría General de la República. (artículo 56).

En relación con lo señalado precedentemente, es menester recordar que la ley Orgánica Constitucional del Ministerio Público en su artículo 17, letra d) dispone que le corresponde al Fiscal Nacional, mediante la dictación de uno o más reglamentos, determinar la forma de funcionamiento de las fiscalías regionales y demás unidades del Ministerio Público.

En consecuencia, al asignar las funciones que deberán cumplir cada una de las unidades administrativas que se contemplan en el artículo 20 de la ley, el Fiscal Nacional debería proceder a identificar los cargos cuya función consista en la administración y/o custodia de bienes o dineros a fin de que esos funcionarios procedan a rendir fianza tan pronto como ingresen a la Institución. Corresponde tener presente que por expresa disposición del artículo 69 de la ley 10.336, los Jefes de Servicio son solidarios de la responsabilidad que pudiere afectar a dichos funcionarios cuando permiten que entren a desempeñar sus cargos sin cumplir con la citada obligación. 
Por otra parte, la Ley de Administración Financiera del Estado, le otorga a la Contraloría General de la República las siguientes atribuciones en esta materia.

Fiscalizar el cumplimiento de las disposiciones legales y reglamentarias que dicen relación con la administración de los recursos del estado (artículo 52, inciso $1^{\circ}$ ).

Efectuar auditorías para verificar la recaudación, percepción e inversión de sus ingresos y de las entradas propias de la Institución (artículo 52, inciso $1^{\circ}$ ).

Exigir los informes necesarios que le permitan la comprobación de los ingresos y gastos correspondientes (artículo 53).

El examen y juzgamiento de las cuentas de conformidad con las normas de su ley orgánica (artículo 54).

Para estos efectos, toda cuenta será examinada, finiquitada o reparada en un plazo que no exceda de un año, contado desde la fecha de su recepción por la Contraloría General (artículo 58, inciso $1^{\circ}$ ). Vencido el plazo de un año, la responsabilidad civil del cuentadante y la que pueda afectar a terceros, ya no es posible hacerla efectiva mediante un juicio de cuentas; sin perjuicio que la responsabilidad civil y penal continúan sometidas a las normas legales comunes (artículo 96 , inciso $2^{\circ}$, ley 10.336 ).

\section{0.- Principios de Servicialidad y Continuidad}

Al disponer la Constitución Política en su artículo $1^{\circ}$, inciso $2^{\circ}$, que el Estado esta al servicio de la persona humana y su finalidad es promover el bien común, consagra el principio de "Servicialidad", en virtud del cual sus órganos e Instituciones del Estado no constituyen un fin en si mismo, sino el medio que la sociedad se da con el fin de satisfacer sus necesidades.

Consecuencia del principio anotado, lo constituye el principio de la "continuidad", en virtud del cual la Constitución Política en su artículo $19 \mathrm{~N}^{\circ} 16$, prohibe a los funcionarios del estado declararse en huelga.

En estrecha relación con lo señalado y con el objeto de asegurar la continuidad del servicio, el derecho administrativo reconoce la figura de la subrogación, la que procede por el sólo ministerio de la ley cuando el funcionario de que se trate, por cualquier motivo, se encuentra impedido de desempeñar el cargo. Por regla general la subrogación opera según el orden de jerarquía, aún cuando tratándose de cargos de exclusiva confianza, la ley autoriza a la autoridad a fijar un orden de subrogación diferente.

La ley del Ministerio Público en sus artículos 23 y 37 trata la subrogación del Fiscal Nacional y Regional, respectivamente.

La única diferencia que existe con la subrogación contemplada en los estatutos Administrativos de los funcionarios públicos y municipales, dice relación en que, a falta de una designación expresa, el Fiscal Nacional es subrogado por el Fiscal Regional más antiguo y éste por el Fiscal Adjunto más antiguo. 


\section{Roberto Saldías Pizarro - Ministerio Público...}

\section{BIBLIOGRAFÍA}

1.- Constitución Política de la República de Chile, Editorial Jurídica de Chile, 1993.

2.- Constitución Política de la República de Chile. Concordancias, Antecedentes y Jurisprudencia. Pfeffer Urquiaga. Emilio. Editorial Jurídica Cono Sur Ltda., 1999.

3.- Mensaje del Presidente de la República N 98-334, de 15 de noviembre de 1996, sobre el proyecto de ley que reformó la Constitución Política y creo el Ministerio Público.

4.- Mensaje del Presidente de la República N 11-337, de 23 de marzo de 1998 , sobre el proyecto de ley que creo el Ministerio Público.

5.- Mensaje del' Presidente de la República N 110-331, de 9 de junio de 1995 , sobre proyecto de ley que establece un nuevo Código de Procedimiento Penal.

6.- Primer Informe de la Comisión de Constitución, Legislación, Justicia y Reglamento del Senado, recaído en el proyecto de ley, segundo trámite constitucional, que establece la ley del Ministerio Público.

7.- Segundo Informe de la Comisión de Constitución, Legislación, Justicia y Reglamento del Senado, recaído en el proyecto de ley, en segundo trámite constitucional, que establece la ley del Ministerio Público. blico.

8.- Ley N 19.519, que reformó la Constitución Política y creo el Ministerio Pú-

9.- Ley N¹9.640, Orgánica Constitucional del Ministerio Público.

10.- Ley N²18.575, Orgánica Constitucional de Bases Generales de la Administración del Estado. pública.

11.- Ley N¹0.336, Orgánica Constitucional de la Contraloría General de la Re-

12.- Decreto Ley $N^{\circ} 1.263$, de 1975, Orgánica de Administración Financiera del Estado.

13.- DE LA BARRA COUSIÑO, Rodrigo, "La Reforma Procesal Penal en Chile: El Ministerio Público, Antecedentes y Desafíos", en Gaceta Jurídica, año 1999/ febre$\mathrm{ro} / \mathrm{N}^{\circ} 224$.

14.- DE LA BARRA COUSIÑO, Rodrigo, "Sistema Inquisitivo Versus Adversarial; Cultura Legal y Perspectivas de la Reforma Procesal Penal " Material entregado en Diplomado.

15.- El Ministerio Público, Publicación basada en los trabajos publicados en la Revista de Ciencias Penales. Cono Sur Ltda., 1995. 
Revista de Derecho - U. Católica del Norte - Campus Guayacán - 2000

16.- GARCíA DE ENTERRÍA, Eduardo y Tomás Ramón Fernández. "Curso de Derecho Administrativo I" Sexta Edición, Editorial Civitas, Madrid 1993.

17.- MARTINEZ DALMAU, Ruben, Aspectos Constitucionales del Ministerio Público Universitat de Valencia, Tirant lo Blanch y Universitat de Valencia, 1999.

18.- REYES RIVEROS, Jorge, "EI Principio de Juridicidad y la Modernidad", Trabajo no publicado.

19.- SILVA CIMMA, Enrique Derecho Administrativo Chileno y Comparado, Editorial Jurídica de Chile, 1995.-

20.- SOTO KLOSS, Eduardo. Derecho Administrativo. Bases Fundamentales. Tomo II, El Principio de Juridicidad, Editorial Jurídica de Chile, 1996. 